\title{
Is temporomandibular joint disorder common in Indian women: tick to talk and chew to lock?
}

\author{
Ballal CV. ${ }^{1}$, Basavannaiah S. ${ }^{2}$ \\ ${ }^{1}$ Dr. C. Venkatesh Ballal, Associate Professor, ${ }^{2}$ Dr. Sphoorthi Basavannaiah, Assistant Professor; both authors are \\ attached with Department of ENT, Subbaiah Institute of Medical Sciences, NH-13, Purle, Holebenavalli Post, Shimoga, \\ Karnataka, India.
}

Corresponding Author: Dr. Sphoorthi Basavannaiah, Assistant Professor, Department of ENT, Subbaiah Institute of Medical Sciences, NH-13, Purle, Holebenavalli Post, Shimoga, Karnataka, India. E-mail: sphoorthi86@rediffmail.com

\begin{abstract}
:
Introduction: Temporomandibular joint (TMJ) is a sliding hinge that connects jawbone to the skull. The exact cause of TMJ disorder in a person is often difficult to determine as the pain may be due to varied factors ranging from clench teeth to caries causing click sound to ache on chew. Women are the only ones to shoulder both the burden and baggage of life on their shoulders very gracefully and during this process they often tend to neglect their health while dealing with various aspects and chapters in life. Objective: To find out the root cause of this disorder and to edify women to eradicate the "angst" regarding false pretentions of this condition. Methodology: 73 women were clinically evaluated and diagnosis was made and treated accordingly from ENT point of view. Results: TMJ arthritis was found to be the cause for TMJ disorder with an add-on of stress in women between 20-35 years of age due to unintentional usage of one side of jaw while chew, who presented with tenderness in and around the jaw and referred pain to the ear. Conclusion: To break the illusionary bubble that runs in the mind of every woman when the basics of the joint motion is restricted which initially leads to pain and can further cause irrevocable complications prior to giving second thought pertaining to the actual facts behind its occurrence.
\end{abstract}

Keywords: Temporomandibular joint, Illusion, Stress, Disorder, Cancer.

\section{Introduction:}

TMJ disorders appear meek with varied intricacy. This disorder either gets unnoticed, unrecognised, neglected or missed as it is difficult and dicey to detect. In India, women are only meant to persist but are not given a chance to prosper and they have only managed to subsist as survivors. Adding to it, women's health is often compromised time and again which has to be actually prioritised as they are not just busy multitasking but have a major role to play in the conundrum of providing and sustaining life.

There is not just single but diverse aetiology and presentations with pain either limited to the joint per se or referred elsewhere to the surrounding structures [1, 2]. It ranges from "click or tick" sound heard while on yawning /opening/closing mouth, radiating pain to neck/back/ shoulders, pain on munching, chewing, biting, eating, speech related issues (unable to talk),

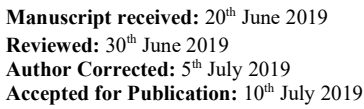




\section{Original Research Article}

- To note down the region most commonly involved in the disease progression.

- To find out if any aggravating factors involved in the disease evolution.

- To evaluate the type of pain and the onset of this condition.

- To provide education to the women regarding its occurrence and impact on life.

\section{Materials and Methods:}

Study design: Descriptive study.

Place of study: Tertiary Care Hospital, Subbaiah Institute of Medical Sciences, Shimoga.

Study period: 1 year (from March 2018 to March 2019).

Selection criteria: A random sample of 73 women who consulted the ENT outpatient department were clinically evaluated.

Inclusion criteria: Only women were considered for the study. Age group from 20-65 years were considered for the study.

\section{Results:}

The observations drawn from the study are depicted in the form of results by means of diagrammatic representation below-

Table-1: Shows causes of TMJ disorder

\begin{tabular}{|l|c|}
\hline \multicolumn{1}{|c|}{ Causes } & Number of patients \\
\hline Caries tooth & 5 \\
\hline Eagle's syndrome & 4 \\
\hline Glossopharyngeal neuralgia & 3 \\
\hline Growth/ mass/ tumor in the oral cavity oropharynx & 6 \\
\hline Gum disease & 3 \\
\hline Migraine & 9 \\
\hline Oral submucous fibrosis & 5 \\
\hline Sinus disease & 4 \\
\hline TMJ arthritis & $\mathbf{3 4 ( 4 7 \% )}$ \\
\hline Total & $\mathbf{7 3}$ \\
\hline
\end{tabular}

Table-2: Shows age group wise distribution of this condition.

\begin{tabular}{|c|c|}
\hline Age group (years) & Number of patients \\
\hline $20-35$ years & 43 \\
\hline $35-50$ years & 19 \\
\hline $50-65$ years & 11 \\
\hline Total & $\mathbf{7 3}$ \\
\hline
\end{tabular}

Exclusion criteria: Men and children were excluded from the study. Age group of $<20$ years and $>65$ years were excluded from the study.

Procedure of the study: Over a period of 1 year, a random sample of 73 women who consulted ENT outpatient department with vague and varied complaints as listed below in Table 3 were clinically evaluated after taking a thorough history.

Following which a probable diagnosis was made. The relevant investigations; wherever necessary was done to arrive at a diagnosis.

Treatment was given based on the diagnosis which was mainly conservative line of management. Surgical line of management was adapted wherever and whenever needed. Informed written consent was taken during the study period.

Ethical clearance has been taken from Institutional Ethics Committee before the start of the study. 
Table-3: Shows patients based on clinical presentation.

\begin{tabular}{|l|c|}
\hline Symptomatology & Number of patients \\
\hline Pain in and around the ear & 10 \\
\hline Headache & 7 \\
\hline Radiation of pain to neck, back and shoulders & 4 \\
\hline Difficulty or pain on chewing, biting, munching, grinding food & 2 \\
\hline Difficulty or pain to talk or speak & 8 \\
\hline $\begin{array}{l}\text { Difficulty or pain or jaw gets stuck or lock on opening or closing mouth while } \\
\text { yawning }\end{array}$ & $\mathbf{2}$ \\
\hline Click or tick sound or grating sensation while opening or closing mouth & $\mathbf{2 1 ~ ( 2 9 \% )}$ \\
\hline Pain in the pre-auricular region or pain or tenderness in the jaw region & 4 \\
\hline Hemi-facial pain & $\mathbf{7 3}$ \\
\hline Total & \\
\hline
\end{tabular}

Table-4: Shows aggravating factors for the evolution of this condition.

\begin{tabular}{|l|c|}
\hline Various factors causing onset of this condition & Number of Patients \\
\hline $\begin{array}{l}\text { Physical injury or h/o any trauma or \# or iatrogenic cause: any mastoid or dental } \\
\text { surgery }\end{array}$ & 6 \\
\hline Professional violinists & 4 \\
\hline Any activity trigger- nail/ pen/pencil bitting & 2 \\
\hline Autoimmune cause/ genetic cause/ anatomical defects & 17 \\
\hline Stress & 5 \\
\hline Habitual movements of jaw- either sideways, tight clench and Bruxism & $\mathbf{2 9}(\mathbf{4 0} \%)$ \\
\hline More usage of one side of the jaw or chews more on one side & $\mathbf{3}$ \\
\hline Any other associated acquired conditions- Rheumatoid arthritis, Osteoarthritis. & $\mathbf{2}$ \\
\hline Past h/o similar complaints & $\mathbf{4}$ \\
\hline Intake of any medications or supplements & $\mathbf{7 3}$ \\
\hline Total & \\
\hline
\end{tabular}

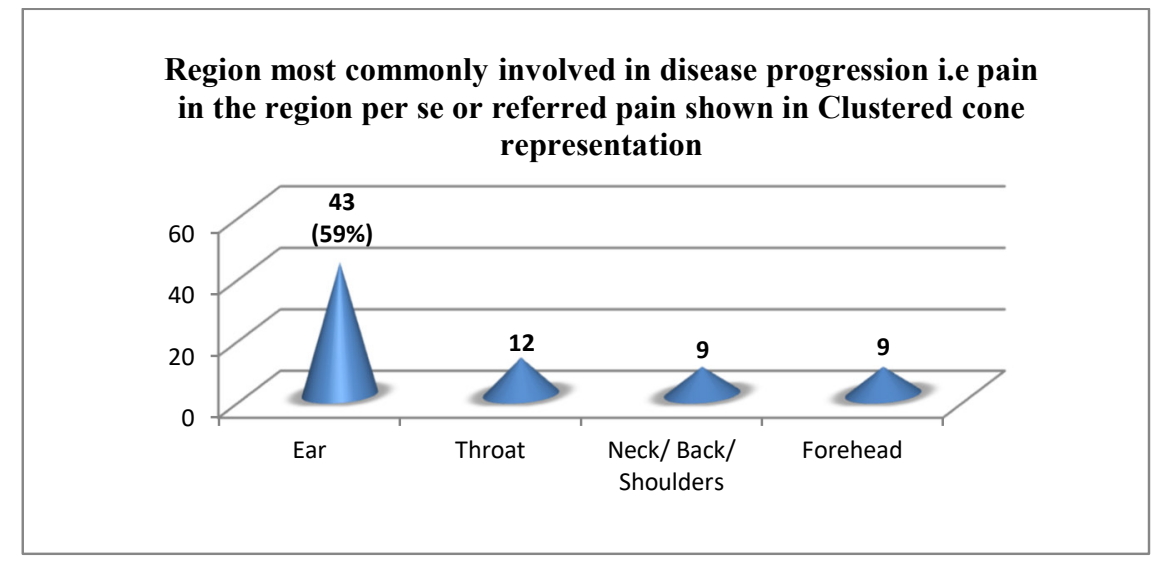

Figure-1: Among them under Ear (TMJ arthritis- 34, Growthin oral cavity or oropharynx- 6, OSMF-3), Throat (Caries5, Eagle's syndrome-4, Glossopharyngeal neuralgia- 3), Neck/Back/ Shoulders (Sinus disease- 4, Gum disease- 3, OSMF- 2) and Forehead (Migraine-9). 
Original Research Article

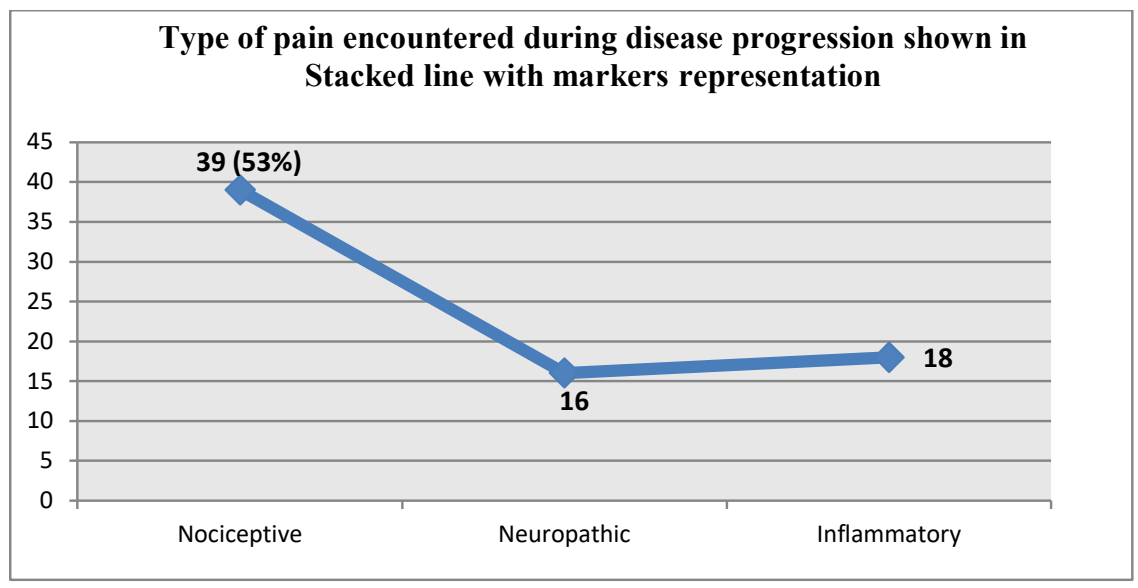

Figure-2: Among them under Nociceptive (TMJ arthritis- 34, OSMF- 5), Neuropathic (Glossopharyngeal neuralgia- 3, Eagle's syndrome- 4, Migraine-9) and Inflammatory (Caries- 5, Sinus disease- 4, Gum disease- 3, Growth in oral cavity and oropharynx-6).

\section{Discussion:}

Temporomandibular joint is a sliding hinge joint that connects jaw to the skull. Its disorders have a varied presentation where the exact cause is often difficult to determine. It has a multifactorial aetiology making it difficult and sometimes tricky to arrive at a diagnosis. In most cases, pain and discomfort associated with TMJ disorders is temporary and can be relieved with selfmanaged care or nonsurgical treatments. Surgery is a last resort after conservative measures have failed, but is beneficial only in some people with TMJ disorders [5, 6]

The parts of the bones that interact in the TMJ are covered with cartilage and are separated by a small shock-absorbing disk, which normally keeps the movement smooth. Painful TMJ disorder scan occur if: disk erodes or moves out of its proper alignment, joint's cartilage is damaged by arthritis, joint is damaged by a blow or any other impact, most of the cases the cause isn't clear. Factors that may increase the risk of developing TMJ disorders include: Rheumatoid arthritis, Osteoarthritis, Jaw injury, chronic grinding or clenching of teeth, certain connective tissue diseases that affect TMJ [7].

As per the study, nearly $50 \%$ of patients were found to have TMJ arthritis i.e. $47 \%$ as most common cause for TMJ disorder from ENT point of view. These findings correlates to certain extent with few of the studies mentioned here [8,9]. The gender predisposition is most often seen in women due increased levels of estrogen. In the present study too, nearly $60 \%$ of women had most common age preponderance of 20-35 years $(59 \%)$ of affiliation of this condition. This fact matches with the studies as mentioned here $[10,11]$.
There is a variety of symptomatology and clinical presentation of TMJ disorders as mentioned above but if there is no pain or no limitation of movement associated with jaw, there is no need of treatment for TMJ disorder. Medical attention is sought if there is persistent pain or tenderness in the jaw or if unable to open or close jaw completely. With a wide range of symptomatology for this condition, (29\%) women presented with pain in the preauricular region/ pain and tenderness over the jaw in this study, which correlates with studies mentioned here $[12,13]$.

There are plenty triggers for the disease evolution extending from habits to heredity, but in our study (40\%) women presented with excessive usage of one side of the jaw on chewing food, which was unintended as well as inadvertent and stress (23\%) being an additive factor to this condition. As per region involvement in the disease progression that is pain in the region per se or as referred pain, Ear (59\%) is the most common region to involve that is nearly in $60 \%$ of women. These findings are closest with studies mentioned here $[14,15]$.

Types of pain are classified as: Nociceptive: represents the normal response to noxious insult or injury of tissues-skin, muscles, visceral organs, joints, tendons or bones. It can be of 2 varities- Somatic: musculoskeletal system which is often well localized (involves joint pain and myofascial pain). Visceral: hollow organs and smooth muscles usually referred $[16,17]$. Neuropathic: pain initiated or caused by a primary lesion or disease in the somatosensory nervous system. Sensory abnormalities range from deficits perceived as numbness to tingling to paraesthesias to 
hypersensitivity. It includes but are not limited to diabetic neuropathy, postherpetic neuralgia, spinal cord injury pain, phantom limb pain, post-stroke central pain $[18,19]$. Inflammatory: as a result of activation and sensitization of the nociceptive pain pathway by a variety of mediators released at a site of tissue inflammation.

The mediators that have been implicated as key players are pro-inflammatory cytokines: IL-1 alpha, IL- 1 beta, IL-6,TNF- alpha, chemokines, reactive oxygen species, vasoactive amines, lipids, ATP, acid and other factors released by infiltrating leukocytes, vascular endothelial cells or tissue resident mast cells. It includes appendicitis, RA, IBD, Herpes zoster [20]. With disease spread, type of pain encountered is Nociceptive stimuli $(53 \%)$ which correlates with studies mentioned here $[16,17]$.

Investigations: Dental X-rays to examine teeth and jaw, CT scan provides detailed images of the bones involved in the joint, MRI reveals problems with the joint's disk or surrounding soft tissue, TMJ arthroscopy is done wherein a small cannula is inserted into the joint space and anarthroscope is then passed to view the area and to help determine a diagnosis [21].

Treatment: In some cases, the symptoms of TMJ disorders may go away without treatment. If symptoms persist, variety of treatment options, often more than one can be applied at the same time. These medications help to relieve the pain associated with TMJ disorders: Pain relievers and Anti-inflammatory: If over-thecounter pain medications aren't enough to relieve TMJ pain, stronger pain relievers for a limited time such as Ibuprofen is prescribed [22]. Tricyclic antidepressants (TCA): Amitriptyline is used mostly for depression, but in low doses, they're sometimes used for pain relief, controls bruxism and sleeplessness [23]. Muscle relaxants: Sometimes used for a few days or weeks to help relieve pain caused by TMJ disorders created by muscle spasms [24] Combination of analgesics with muscle relaxants are now the present choice for pain relief and this combination was given to 34 patients with TMJ arthritis along with educating and counselling them the do's and don'ts of usage of the TMJ.

Most of those who followed up had improved results and were symptomatically relieved. In 7 patients with Glossopharyngeal neuralgia and Eagle's syndrome they were treated symptomatically with Analgesics, TCA. They were counselled for not considering surgical mode of treatment such as Neurectomy and Styloidectomy as the success rates are not as expected. While in 9 patients with Migraine were given Calcium antagonists (Flunarizine) along with Analgesics for a brief period of time. They improved well when followed up as they were advised to bring in lifestyle and dietary changes, as Migraine somewhere down the line is directly proportional to GERD [22, 23, 24].

Nondrug therapies: Oral splints or mouth guards (occlusal appliances): People with jaw pain will benefit from wearing a soft or firm device inserted over their teeth, but reasons why these devices are beneficial is not well-understood.In 5 patients with OSMF, intralesional injection to both retromolartrigone was given with mixture of Triamcinolone $4 \mathrm{mg}$ with Hyaluronidase 1500 units weekly for 4 weeks [2, 3]. Only 3 patients showed improvement in mouth opening, while rest 2 did not show much improvement.

While Hexter's mouth retractor that enhances mouth opening was suggested to the 2 patients, but due to financial constraints they neither preferred mouth guard nor any surgical intervention nor were later lost to follow up [13]. Counselling and providing education: To bring in lifestyle modification scan help understand the factors and behaviours that may aggravate pain, so as to avoid them.

The following tips are helpful to reduce symptoms of TMJ disorders: Usage of both sides of the jaw equally, usage of molars to break down hard food stuff, avoid overuse of jaw muscles, eat soft foods, cut food into small pieces, avoid chewing gum, stretch and massage exercises are done to strengthen jaw muscles, applying warm, moist heat or ice to the side of face may alleviate pain, avoid tobacco/ betel nut chewing etc. Avoid teeth clenching or grinding, leaning on your chin, or biting fingernails, Becoming more aware of tension-related habits- clenching jaw, grinding teeth or chewing pencils will help reduce their frequencyand these were the highlights suggested by us during the study $[15,16]$. Moreover they were also provided an educative counselling explaining the pros and cons of the condition and also the do's and dont's to be mandatorily implemented and adapted in their day to day routine.

Surgical procedures: Corticosteroid injections \& Botulinum toxin Type A injections to the joint, Arthrocentesis, Modified condylotomy, Arthrotomy are all done to repair or replace the joint when conservative treatment has failed to respond. In the present study, none of the above mentioned surgical procedures were adapted for symptomatic relief. Dental intervention was sent for caries and gum disease that is in 8 patients. In case of growth in oral cavity/ oropharynx in 6 patients, 
as the patients were already in Stage III/ IV of disease progression, only biopsy taken for tissue diagnosis and were sent for radiation therapy at higher centre. While in 4 cases with Acute maxillary sinusitis, they were treated with conservative line of management among whom 3 were relieved symptomatically but 1 patient showed up with recurrent maxillary sinusitis, wherein mini FESS was done for patient's relief of symptoms as mentioned here $[17,18]$.

Recommendations: Women are often seen to have encountered this condition due to various factors-

1. Surge of estrogen is at a higher range in women during their active reproductivity years (20-35 years), hence occurrence of this condition is more during those years.

2. Stress which seems like a minor stimulator rather causes major setback in the day to day routine as women tend to get hassled and frassled very soon for very tiny winy things. Hence, stress acts as a synergistic factor to the already existing precursor of this condition

3. TMJ is concerned with prominent actions like open, close, eat, talk etc. Once these actions are compromised, its normal human tendency as the mind-set goes towards some inevitable thought of "cancer" that must have caused this condition, hence jeopardising every situation in life in one way or other which is not true.

Inputs for Insight: As per the literature search, we have not come across any such study which says that TMJ disorder is somewhere linked to usage of one side of jaw on during chewing food. As a matter of fact, the dread of "cancer" which is the present day alarm which has been lingering in their minds with every passing day like a swinging sword on their heads to get beheaded any time is somehow buried down. We strongly tried to break the "illusionary bubble" by advising them the "words of wisdom" regarding the do's and don'ts that has to be followed judiciously on daily basis that is been running in the thought process of every woman when the "nuts and bolts" of the joint motion is limited prior to analysing the genuine specifics behind its existence.

\section{Conclusions:}

Despite multifactorial aetiology, this habit of jaw usage was unintentionally neglected considering various unrelated "self- conclusions" drawn through social media prior to proper consultation which was sorted in this study. Plus, eliminating the "psychological illusion" that they have been suffering from an uncommon and unresolvable condition that has led to this disorder especially malignancy which is the present day "epidemic malady" has also been dealt in this study. This fear did act as a "food for stimulation" leading to further health complications which were erased in this study. Hence, we tried to enlighten women about adapting and explaining the significance of equal usage of both sides of the jaw while chewing food thus relieving their delusion from their minds, stress surgeand mental agony.

\section{Funding: Nil, Conflict of interest: Nil} Permission from IRB: Yes

\section{References:}

1. Kraus S. Temporomandibular disorders, head and orofacial pain: cervical spine considerations. Dental Clinics. 2007;51(1):161-93. DOI: https://doi.org/10. 1016/j.cden.2006.10.001

2. Cooper BC, Kleinberg I. Examination of a large patient population for the presence of symptoms and signs of temporomandibular disorders. Cranio. 2007; 25 (2):114-26. DOI:10.1179/crn.2007.018.

3. Fricton J. Myogenoustemporomandibular disorders: Diagnostic and management considerations. Dent Clin North Am. 2007;51(1):61-83.PMID: 17185060 DOI: $10.1016 /$ j.cden.2006.10.002.

4. Scrivani SJ, Keith DA, Kaban LB. Temporomandibular disorders. N Engl J Med. 2008;359 (25): 2693-705. DOI: 10.1056/NEJMra0802472.

5. Tanaka E, Detamore MS, Mercuri LG. Degenerative disorders of the temporomandibular joint: etiology, diagnosis, and treatment. J Dental Res. 2008;87(4): 296-307.DOI:https://doi.org/10.1177/ 15440591080 8700406

6. Wright EF, North SL.Management and treatment of temporomandibular disorders: a clinical perspective. J Man ManipTher. 2009;17(4):247-54.DOI:10.1179/ 106698109791352184.

7. Ingawalé $\mathrm{S}$, Goswami $\mathrm{T}$. Temporomandibular joint: disorders, treatments, and biomechanics. Ann Biomed Eng. 2009 ;37 (5): 976-96. DOI: 10.1007/s 10439- 009-9659-4.

8. Oral K, Bal Küçük B, Ebeoğlu B, Dincer S. Etiology of temporomandibular disorder pain. Agri. 2009;21 (3): 89-94. 
9. de Godoi Gonçalves DA, Dal Fabbro AL, Campos JA, Bigal ME, Speciali JG. Symptoms of temporomandibular disorders in the population: an epidemiological study. J Orofac Pain. 2010 Summer; 24(3):270-8.

10. Martins RL, Palma AJ, Marquardt EJ, Gordin TM. . Temporomandibular disorders: a report of 124 patients. J Contemp Dent Pract. 2010;11(5):071-8.

11.Lim PF, Smith S, Bhalang K, Slade GD, Maixner W. Development of temporomandibular disorders is associated with greater bodily pain experience. Clin J Pain. 2010;26(2):116-20. DOI: 10.1097/AJP.0b $013 \mathrm{e} 3181 \mathrm{c} 507 \mathrm{ef}$.

12. Sharma S, Gupta DS, Pal US, Jurel SK. Etiological factors of temporomandibular joint disorders. Natl J Maxillofac Surg. 2011;2(2):116-9. DOI: 10.4103/ 0975- 5950.94463.

13. Okeson JP, de Leeuw R. Differential diagnosis of temporomandibular disorders and other orofacial pain disorders. Dent Clin North Am. 2011;55(1): 105-20. DOI: 10.1016/j.cden.2010.08.007.

14. Hoffmann RG, Kotchen JM, Kotchen TA, Cowley T, Dasgupta M, Cowley Jr AW. Temporomandibular disorders and associated clinical comorbidities. Clin J Pain. 2011; 27(3): 268-74. DOI: 10.1097/AJP. 0b013 e31820215f5.

15. Goncalves DA, Camparis CM, Speciali JG, Franco AL, Castanharo SM, Bigal ME. Temporomandibular disorders are differentially associated with headache diagnoses: a controlled study. Clin J Pain. 2011; 27 (7): 611-5. DOI: 10.1097/AJP.0b013e 31820e12f5

16. Martin WJ, Perez RS, Tuinzing DB, Forouzanfar T. Efficacy of antidepressants on orofacial pain: a systematic review. Int $\mathrm{J}$ Oral Maxillofac Surg. 2012;41(12):1532-9. DOI: 10.1016/j.ijom.2012. 09. 001 .

17. Kindler S, Samietz S, Houshmand M, Grabe HJ, Bernhardt O, Biffar R, et al. Depressive and anxiety symptoms as risk factors for temporomandibular joint pain: a prospective cohort study in the general population. J Pain. 2012;13(12):1188-97. DOI: 10. 1016/j. jpain.2012.09.004.

18. Senye M, Mir CF, Morton S, Thie NM. Topical nonsteroidal anti-inflammatory medications for treatment of temporomandibular joint degenerative pain: a systematic review. J Orofac Pain. 2012 Winter; 26(1):26-32.

19. ReiterS, Goldsmith C, Emodi-Perlman A, FriedmanRubin P, Winocur E. Masticatory muscle disorders diagnostic criteria: the American Academy of Orofacial Pain versus the research diagnostic criteria/ temporomandibular disorders (RDC/TMD). J Oral Rehabil. 2012;39(12):941-7. DOI: 10.1111/j. 1365-2842.2012.02337.x.

20.Zakrzewska JM. Differential diagnosis of facial pain and guidelines for management. Br J Anaesth. 2013; 111(1):95-104. DOI: 10.1093/bja/aet125.

21. Nascimento MM, Vasconcelos BC, Porto GG, Ferdinanda G, Nogueira CM, Raimundo RC. Physical therapy and anesthetic blockage for treating temporomandibular disorders: a clinical trial. Med Oral Patol Oral Cir Bucal. 2013;18(1):e81-e85.DOI: 10.4317/medoral.17491.

22. Machado E, Bonotto D, Cunali PA. Intra-articular injections with corticosteroids and sodium hyaluronate for treating temporomandibular joint disorders: a systematic review. Dental Press J Orthod. 2013;18(5):128-33.

23. Gauer RL, Semidey MJ. Diagnosis and treatment of temporomandibular disorders. Am Fam Physician. 2015;91(6):378-86.

24. Oyetola EO, Adesina OM, Oluwadaisi A, Adewale A, Adewole O, Anizoba E. Temporomandibular Joint Pain: Clinical Presentations and Response to Conservative Treatments in a Nigerian Tertiary Hospital. J IntSocPrev Community Dent. 2017;7(3): 98-103. PMID: 28584778 DOI: 10.4103/jispcd. JISPCD 7 17.

\section{How to cite this article?}

Ballal CV, Basavannaiah S. Is temporomandibular joint disorder common in Indian women: tick to talk and chew to lock?. Trop J Ophthalmol Otolaryngol.2019;4(3):212-218.doi:10.17511/jooo.2019.i03.06 